\title{
Erratum
}

\section{Aspects of biotechnology in a united Germany (Mini-review)}

\author{
Rolf D. Schmid', Hans-Jürgen Rehm ${ }^{2}$ \\ ${ }^{1}$ Gesellschaft für Biotechnologische Forschung (GBF), W-3300 Braunschweig, Federal Republic of Germany \\ ${ }^{2}$ Institute of Microbiology, University of Münster, W-4400 Münster, Federal Republic of Germany \\ Appl Microbiol Biotechnol 35:135-143
}

On p. 136, right column, in the paragraph "The federal government and the state government" the biotechnology RD support for 1989 was given as DM 1.2 billion. This should read DM 232 million. 